Madrygal. Revista de Estudios Gallegos

ISSN: $1138-9664$

\title{
Galiza vista por Archer Milton Huntington: A Note-Book in Northern Spain (1898)
}

\author{
Teresa López ${ }^{1}$
}

Recibido: 22 de xullo de 2019 / Aceptado: 15 de marzo de 2020

Resumo. En 1898, Archer Milton Huntington, futuro fundador da Hispanic Society of America, publica A Note-Book in Northern Spain, un libro de viaxes cuxos capítulos iniciais están dedicados a Galiza, especialmente á Coruña e a Santiago de Compostela. O obxectivo deste artigo é analizar a imaxe de Galiza plasmada no volume, no marco da representación de España construída polo ollar anglosaxón, particularmente o norteamericano, reflectido na literatura de viaxes, na incipiente produción académica hispanista e na moda hispana que se expande polas artes en Estados Unidos na viraxe do século, coincidindo cun momento de conflicto político entre ambos estados. Mostraremos como A Note-Book in Northern Spain combina as impresións directas do viaxeiro sobre Galiza, coa información proveniente de fontes librescas, singularmente de Galicia (1888) de Manuel Murguía, obra referente do rexionalismo galego, e de Recuerdos de un viaje a Santiago de Galicia (1880) de Fidel Fita e Aureliano Guerra, dos estudos xacobeos. A análise terá en conta a información complementaria das viaxes de Huntington a España e a Galiza recollida nos seus diarios.

Palabras chave: Archer Milton Huntington; literatura de viaxes; viaxeiros anglosaxóns; identidade galega.

\section{[es] Galicia vista por Archer Milton Huntington: A Note-Book in Northern Spain (1898)}

Resumen. En 1898, Archer Milton Huntington, futuro fundador de la Hispanic Society of America, publica $A$ NoteBook in Northern Spain, un libro de viajes cuyos capítulos iniciales están dedicados a Galicia, especialmente a Coruña y a Santiago de Compostela. El objetivo de este artículo es analizar la imagen de Galicia plasmada en el volumen, en el marco de la representación de España construida por la mirada anglosajona, particularmente la norteamericana, reflejada en la literatura de viajes, en la incipiente producción académica hispanista y en la moda hispana que se extiende por las artes en Estados Unidos en el cambio de siglo, coincidiendo con un momento de conflicto político entre los dos estados. Mostraremos como A Note-Book in Northern Spain combina las impresiones directas del viajero sobre Galicia con la información obtenida de fuentes librescas, singularmente de Galicia (1888) de Manuel Murguía, obra referente del regionalismo gallego, y de Recuerdos de un viaje a Santiago de Galicia (1880) de Fidel Fita y Aureliano Guerra, de los estudios jacobeos. El análisis tendrá en cuenta la información complementaria de los viajes de Huntington a España y a Galicia recogida en sus diarios.

Palabras clave: Archer Milton Huntington; literatura de viajes; viajeros anglosajones; identidad gallega.

\section{[en] Galiza Seen by Archer Milton Huntington: A Note-Book in Northern Spain (1898)}

Abstract. In 1898, Archer Milton Huntington, future founder of the Hispanic Society of America, published $A$ NoteBook in Northern Spain, a travel book whose initial chapters are dedicated to Galicia, especially to Coruña and Santiago de Compostela. The aim of this article is to analyze the image of Galicia captured in the volume, within the framework of the representation of Spain built by the Anglo-Saxon gaze, particularly the North American one, reflected in travel literature, in the incipient Hispanic academic production and in the Spanish Craze, that spans the arts in the United States at the turn of the century, coinciding with a time of political conflict between the two states. We will show how $A$ NoteBook in Northern Spain combines the direct impressions of the traveler about Galicia with the information obtained from book sources, very uniquely from Galicia (1888) by Manuel Murguía, a reference work of Galician regionalism, and of Recuerdos de un viaje a Santiago de Galicia (1880) by Fidel Fita and Aureliano Guerra, of the Jacobean studies.

1 Universidade da Coruña. Departamento de Letras, Grupo de Investigación Lingüística e Literaria Galega (ILLA). Correo-e: lopez@udc.gal; https://orcid.org/0000-0003-3888-7092. 
The analysis will take into account additional information on Huntington's trips to Spain and Galicia, collected in his diaries.

Keywords: Archer Milton Huntington; Travel Literature; Anglo-Saxon Travellers; Galician Identity.

Sumario. 1. Viaxeiros e viaxeiras por España no século XIX. 1.2. Viaxeiros e viaxeiras norteamericanas. 2. Archer Milton Huntington (1870-1955). 3. As primeiras viaxes de Huntington a España. 3.1. A preparación da viaxe. 3.2. As viaxes. 3.2.1. De viaxe por Galiza. 4. Un libro de viaxes: A Note-Book in Northern Spain (1898). 5. España e Galiza no Note-Book. 5.1. Unha idea de España. 5.2. Unha idea de Galiza. 5.2.1. O celtismo: Galiza e Irlanda. 5.2.2. Historia, arqueoloxía e folclore. 5.2.3. As cidades. 5.2.4. Lingua e literatura. 5.2.5. A experiencia da viaxe 6. Cabo. 7. Referencias bibliográficas.

Como citar: López, T. (2020): “Galiza vista por Archer Milton Huntington: A Note-Book in Northern Spain (1898)", en Madrygal. Revista de Estudios Gallegos 23 Núm. Especial, pp. 235-250.

Galicia es una de las mas desconocidas partes de la península, que rara vez frecuentan los españoles y mas raramente los estrangeros. La marcha de estos últimos, es mas generalmente al Mediodia, y en especial a Andalucia, único sitio donde se cree encontrar arte y naturaleza hermosa. Por lo general se da al Norte de España poca atención

Alexandro Ziegler (1852) apud Manuel Murguía na Historia de Galiza (1865)

\section{Viaxeiros e viaxeiras por España no sécu- lo XIX}

A pesar de que España non formase parte do circuíto do Grand Tour, foron moitos os viaxeiros e algunhas as viaxeiras que se achegaron á Península e deixaron escrita (e ás veces publicada) a crónica das súas impresións. No final do século XVIII prevalecía a imaxe de España como un país salvaxe e illado, atrasado fronte aos ventos de modernidade que inundaban Europa, e só co novo século comezará a atraír algúns viaxeiros movidos polo afán de coñecer de primeira man o país exótico e orientalizado que o imaxinario romántico estaba a crear e, en menor medida, outros guiados por razóns ben máis materiais, principalmente polas posibilidades de explotación dos recursos naturais e de adquisición de bens artísticos (Jacobs s.d.: 1).
Con todo, é a imaxe dun país fóra da modernidade, arrasado polo despotismo político e polo fanatismo relixioso, e, en certa forma, primitivo, a que prevalece nesta centuria, alimentada aínda pola lenda negra creada polos británicos. Por isto, no final do século XIX o viaxeiro continúa a procurar na Península "as terras que Clio esquecera ou não destruira: as terras mergulhadas num passado imemorial ou as últimas terrae incognitae" (Machado e Pageaux 1988: 42).

A procedencia das persoas que visitan España é maioritariamente europea, con predominio das naturais do Reino Unido, o país que inventara o Grand Tour. Algúns destes viaxeiros reflectiron en obras literarias que alcanzarán grande popularidade unha imaxe de España que marcará as experiencias de viaxe posteriores, caso de Childe Harold's Pilgrimage (1812-18) de Lord Byron ou Carmen (1845) de Prosper Mérimée. Madrid, Sevilla, Granada, Toledo e Barcelona, son os principais destinos nuns itinerarios de viaxe que privilexian Andalucía e Castela, os dous territorios en que descansará a conformación da idea de España no século XIX. O Romantismo vai construír unha imaxe tópica do español ancorada no orientalismo e no medievalismo, contribuirá á creación de tipos nacionais pintorescos de longa duración (toureiros, xitanos, esmolantes etc.), e fixará a idea de España como un lugar fóra do presente que, por iso mesmo, ofrecía unha experiencia da viaxe emocionante e aberta a unha vivencia aventureira non exenta de perigos, con bandoleiros que podían asaltar o viaxante en calquera momento.

Dúas obras contribuíron de forma singular a proporcionar ao público anglosaxón informacións sobre España e datos sobre a experiencia da viaxe: The Bible in Spain (1843) de George Borrow e A Hand-Book for Travellers in Spain and Readers at Home (1845) de Richard Ford ${ }^{2}$. Se o primeiro pode ser considerado como un testemuño de viaxe que axudou a consolidar a imaxe medievalizada de España, o segundo pretende ser un completo manual de viaxe, con información veraz que completase -aínda que non os superase- os tópicos sobre o país creados polo Romantismo. Borrow foi tamén autor

2 Os títulos completos das obras son The Bible in Spain: the Journeys, Adventures and Imprisonments of an Englishman in an Attempt to circulate the Scriptures in the Peninsula e A Hand-Book for Travellers in Spain and Readers at Home: Describing the Country and the Cities, the Natives and their Manners; the Antiquities, Religion, Legends, Fine Arts, Literature, Sports and Gastronomy. With Notices on Spanish History. As achegas ao xénero de Ford completaranse con Gathering from Spain (1846). 
de The Zincali or An Account of the Gypsies of Spain (1841), unha obra que contribuíu a popularizar o estereotipo romántico do xitano español, e que influíu no interese por España de Huntington, como veremos. Borrow, como Ford, visitou Galiza, e ambos fan parte da pequena nómina de autores de libros de viaxes procedentes do Reino Unido que a incluíron no seu percurso español, xunto con Samuel Widdrington ou o Conde de Carnarvon ${ }^{3}$. Aínda que nesta altura a viaxe por España é presentada, pola influencia do modelo byroniano, como unha experiencia masculina, de vagabundaxe dun suxeito solitario (Gifra-Adoher 2001: 30), algunhas mulleres visitan a Península e publican as súas impresións da viaxe, caso de Lady Louisa Tenison (Castile and Andalucia, 1853), Julia Byrne (Cosas de España, 1866) e Elizabeth Herbert (Impressions of Spain, 1866).

\subsection{Viaxeiros e viaxeiras norteamericanas}

Ao longo do século XIX, entre os visitantes anglosaxóns van ir cobrando paulatina importancia os procedentes dos Estados Unidos, de forma principal a partir da década de 70 , unha afluencia que se viu favorecida pola apertura da liña ferroviaria entre París e Madrid e polo inicio dun período de relativa estabilidade na política española (Kagan 2010: 47) ${ }^{4}$. Con anterioridade, pioneiros ilustrados como John Adams visitaran España no século XVIII, sucedidos polos viaxeiros da xeración romántica procedentes da costa este, membros da elite cultural e política (Gifra-Adoher 2001), como o historiador George Ticknor -que deixaría nos seus diarios testemuño da viaxe realizada en 1818-, o escritor Washington Irving, que reside en Madrid e en Andalucía, o mariño Alexander S. Mackenzie, que visita España en 1827 (Gifra-Adoher 2001), o escritor Henry Longfellow -que inclúe España na súa viaxe de formación por Europa entre os anos 26 e o 29- e o xurista e diplomático Caleb Cushing, que viaxa por España entre 1829 e 1831 (Jaksić 2007). De entre as primeiras viaxeiras norteamericanas, destacará Caroline Cushing, esposa de Caleb, e autora de Letters, Descriptive of Public
Monuments, Scenery and Manners in France and Spain (1832).

O relato das experiencias da viaxe converterase nun dos xéneros de maior éxito, como recoñecía o propio George Putnam, fundador da casa editora onde se publicará o Note-Book (Gifra-Adoher 2001: 35). Irving dará ao prelo en 1832 The Alhambra: Series of Tales and Sketches of the Moors and Spaniards (publicado en 1851 como Tales of the Alhambra), que alcanzará un enorme éxito e será a obra responsábel da exotización e da orientalización da representación de España entre o público anglosaxón, nomeadamente o norteamericano. Cushing publica en 1833 Reminiscences of Spain. The Country, its People, History and Monuments, obra de erudición focada na información histórica; Mackenzie, A Year in Spain, en 1829 e, en 1836, Spain Revisited, obras ambas que deixan translucir o seu interese pola convulsa actualidade política. De Ticknor publicaranse postumamente os seus escritos de viaxe ${ }^{5}$; e a Henry Longfellow a súa estadía española proporcionoulle abondoso material para a súa obra de creación, mais non publicou as súas impresións de viaxe, recollidas en diarios inéditos, estudados por Jaksić (2007).

Por outra parte, algúns destes viaxeiros contribuíron de forma decisiva a sentar as bases do hispanismo norteamericano. Ticknor e Longfellow ocuparon a cátedra Smith de literatura española na Universidade de Harvard, onde o segundo substituíu o primeiro (Fernández Lorenzo 2018: 42) e a través da súa produción académica -Irving coas súas crónicas históricas e biográficas; Ticknor como autor da History of Spanish Literature (1849), obra de referencia mundial no seu tempo; Longfellow, como responsábel de importantes traduciónsavalaron a visión idealizada de España que a literatura de viaxes axudara a crear (Gifra-Adoher 2001).

O hispanismo contribuirá poderosamente á creación dunha conciencia nacional norteamericana (Jaksić 2007), colocando a representación construída de España, mais tamén de Hispanoamérica, como modelo a negativo

3 Autores de Spain and the Spaniards in 1843 (Londres, 1844) e Portugal and Galicia: with a Review of the Social and Political State of the Basque Provinces (Londres, 1848, $3^{\mathrm{a}}$ ed.).

4 Kagan (2010: 48) estima uns 50.000 visitantes norteamericanos en Europa en 1880, unha cifra que subiría até os 125.000 en 1900 .

5 En 1876 Life, Letters and Journals of George Ticknor, en edición de George Hillard e Anna Ticknor, a súa esposa, e xa no século XX Ticknor's Travels in Spain, editado por George Northup (1913). 
dos Estados Unidos (Kagan 1998). Esta contraposición vai verse reforzada logo da guerra hispano-americana de 1898: unha nación católica, monárquica, autoritaria e reaccionaria, fronte a outra protestante, republicana, democrática e progresista, unha caracterización que proporcionaba unha explicación moral para a decadencia (e a derrota) de unha fronte á emerxencia (e o triunfo) da outra.

Se algúns viaxeiros e viaxeiras norteamericanas deixaron testemuños escritos da súa experiencia española, outros van plasmar representacións visuais da súa visita. Artistas como Mary Cassatt, John Singer Sargent e William Merritt Chase viaxan a España a partir da década de 60 (Kagan 2019) e van consolidar nos seus cadros unha imaxe dun espazo exótico habitado por curas, esmolantes, xitanos e mulleres de ollos escuros (Fernández Lorenzo 2018: 43 ), onde cobran protagonismo toureiros e bailaoras de flamenco e paisaxes adornadas con soleadas vilas brancas. Ao tempo, Chase vai desempeñar un papel fulcral na popularización da chamada escola española de pintura (El Greco, Velázquez) e na introdución nos Estados Unidos de pintores contemporáneos como Sorolla e Zuloaga (Kagan 2010) que, entrado o século XX, protagonizarán exitosas exposicións promovidas por Huntington na Hispanic Society (Fernández Lorenzo 2018: 171).

Desta forma, viaxeiros e viaxeiras van construíndo textual -de preferencia en libros de viaxes, mais non só- e visualmente unha idea de España que, se de inicio fora herdeira da lenda negra, logo incorporará a orientalización, a medievalización e o pintoresco como eixos principais, unha representación construída sobre o Sur da Península, singularmente sobre Andalucía. Este ollar sobre España combinará o fascinio polo pasado e o rexeitamento do que representa no presente e proporcionará "[an] arcadian and nostalgic view of Spain as a simple, rural, and motionless country that offered a contrast to the bustling society of the United States" (Gifra-Adoher 2001: 29). En certa forma, a idea de atraso que paira sobre a representación de España -mais tamén de Portugal-, vincúlase a unha autenticidade que os novos modos de vida que a expansión do capitalismo traía consigo estaba a destruír.

A idea de España vixente nos Estados Unidos de finais do século XIX complétase coa descuberta da cultura española -ou hispánica, nunha mestura de elementos españois e mexicanos (Kagan 2010) - pola sociedade norteamericana e o fascinio polas artes, pola música e pola danza española, a denominada Spanish Craze, que terá a súa manifestación arquitectónica na construción de edificios públicos e mansións privadas de estilo español (Spanish Revival) e que vai despertar o interese das grandes fortunas da Gilded Age na adquisición de obras artísticas españolas, incluíndo a importación de monumentos enteiros, trasladados pedra a pedra a Norteamérica (Kagan 2010). Arabella Duvall, a nai de Archer Huntington, tiña na súa residencia un salón mourisco de case 1000 metros cadrados, decorado seguindo a moda orientalizante xerada polos contos da Alhambra de Irving (Fernández Lorenzo 2018: 32). Que esta paixón española era perfectamente compatíbel co rexeitamento do que representaba politicamente España na actualidade demóstrao que un dos maiores importadores de bens artísticos españois fora William Randolph Hearst (Kagan 2010), o magnate da prensa que desde as cabeceiras da súa propiedade encirrara a animadversión contra España no conflito hispanocubano. Por veces este coleccionismo ligado á importación masiva de bens -e próximo do espolio artístico- vai ser xustificado coa idea de que se estaba a preservar un patrimonio que, doutra forma, podería desaparecer (Kagan 2010).

Todas estas circunstancias concorren para explicar a pulsión hispanista que guiará os estudos e motivará as primeiras viaxes a España de Archer Milton Huntington.

\section{Archer Milton Huntington (1870-1955)}

Archer Milton Huntington nacera en 1870 en Nova York como Archer Milton Worsham e, en 1884, logo do matrimonio da súa nai, Arabella, con Collis Porter Huntington, magnate dos transportes e unha das maiores fortunas dos Estados Unidos ${ }^{6}$, converterase en Archer Milton Huntington e en multimillonario herdeiro (Proske 1965, Bennet 2013, Fernández Lorenzo 2018).

A situación económica familiar vai permitir que Archer dedique na súa xuventude tempo e recursos a unha formación académica

6 Propietario da Central Pacific Railroad e dos estaleiros Newport News Shipbuilding and Drydock Company. 
particular e a medida en arte, en historia e en linguas, e á realización de viaxes de estudo e formación. Logo do pasamento de Collis en 1900, a xestión da inmensa fortuna herdada permitirao converterse nun dos maiores filántropos e mecenas norteamericanos das artes no século XX, a través da creación de institucións museísticas (a Hispanic Society of America con sede en New York, mais tamén o Mariner's Museum de Newport News, Virginia, o Golf Museum, tamén en Virginia, o museo de escultura Brookgreen Gardens en Carolina do Sur) e do apoio económico a múltiples iniciativas académicas e culturais, en Estados Unidos e en Europa, moi especialmente en España.

A Hispanic Society of America, fundada en 1904, e para a que inaugura sede no alto Broadway en 1908, fai realidade a idea dun Museo español que fora cobrando forma na mente de Huntington como resultado da conxunción do seu interese pola cultura española, esporeada, ao que parece, a raíz da lectura en 1882 da obra de George Borrow The Zincali (1841), do seu convencemento da importancia dos museos logo da visita, no mesmo ano, á National Gallery na capital británica e ao Museo do Louvre en París, e do contacto directo cunha cultura de lingua española, na visita que realiza a México en 1889 en compañía de seus pais (Proske 1965: 1). A Hispanic Society será a beneficiaria principal das innúmeras adquisicións bibliográficas e artísticas de Huntington, que darán corpo a unha vasta e singular biblioteca, que comprende manuscritos e edicións príncipes de enorme valor, e ao museo de arte español e hispanoamericano da institución (Codding 2000).

Os estudos históricos e filolóxicos de Huntington plasmaranse na publicación da edición/ tradución ao inglés do Poema do Cid (18971908 , en 3 vols. $)^{7}$, o seu contributo académico máis destacado, que lle proporcionará un recoñecemento no hispanismo internacional que se verá acrecentado pola creación dunha colección editorial de facsimilares de manuscritos raros e polo seu apoio económico a publicacións e coleccións académicas especializadas. O seu interese pola literatura incluirá a creación poética, plasmada en varios poe- marios, escolmados en Collected Verse (1953), que en non poucas ocasións combinan a recreación de episodios históricos coas experiencias de viaxe.

O cultivo do coleccionismo artístico e a vocación filantrópica das grandes fortunas da Gilded Age confluirá coa vocación intelectual de Huntington, volcada no hispanismo, dando orixe a iniciativas múltiples e singulares, moitas xestadas nas súas intensas viaxes de formación por España na década de 90.

\section{As primeiras viaxes de Huntington a Es- paña}

\subsection{A preparación da viaxe}

Huntington viaxara a Europa a inicios da década de 80 , porén non será até a década seguinte cando visite España, até en tres ocasións, en 1892, 1896 e 1898, permanecendo en cada oportunidade varios meses no país (Bennet 2013), ás veces con desprazamentos de ida e volta a outros lugares do continente europeo, como mostran as anotacións dos seus Diarios ${ }^{8}$. Estas súas viaxes primeiras a España formaban parte do programa formativo deseñado por el mesmo para coñecer de primeira man aqueles aspectos da cultura que o estudo libresco non podía proporcionarlle: "The thing now is to see with my eyes, not through a page darkly", anotará nos Diarios, a 8 de marzo de 1892, antes de emprender a primeira viaxe.

$\mathrm{Na}$ súa planificación previa, o primeiro obxectivo das viaxes é coñecer as cidades, o campo e a xente. Despois, a adquisición de libros e o estudo académico. Unha prioridade para o coñecemento de primeira man do país e das súas xentes que vai reiterar en diversas ocasións, e que servirá para articular un programa de viaxe que se desenvolverá en varias visitas: "The first trip must be cities, the country and the people. Then book collecting and Library work and last History and Archeology. The will overlap of course but it is best to go with a plan to cover several trips" (Diarios, 1.3.1892, citado tamén por Bennet 2013: 79). O interese polo coñecemento do pobo é de raigame romántica e responde a unha concepción do carácter nacional (Volksgeist) que se presenta

Unha escultura do Cid, realizada por Anna Hyatt Huntington, a segunda esposa de Archer, está colocada no patio da Hispanic Society of America.

8 Os Diarios de Huntington consérvanse na Biblioteca da Hispanic Society of America. Queremos agradecer ao persoal da Biblioteca e ao seu director, Dr. John O’Neill, as facilidades que nos deron para a súa consulta. 
como forxado na historia, de aí a presenza dunha forte componente histórica no Note-Book e na maioría dos libros de viaxes no século XIX.

Da preparación académica de Archer formou parte unha intensa aprendizaxe lingüística, incluído o árabe. Non é difícil aventurar a influencia de Irving na súa convicción da importancia fundamental da cultura árabe para comprender España, ben presente no Note-Book. En 1892 está a recibir clases particulares deste idioma e, na mesma altura, confesa que pensa que ten a mellor biblioteca árabe de Norteamérica (Diarios, 30.1.1892). $\mathrm{O}$ interese polo árabe está directamente relacionado coa súa vocación polos estudos filolóxicos, que o ocuparán de maneira notábel na década de 90 ("I do very well now with Arabic and will soon have all I want of it for philological work in Spain and Portugal", Diarios, 17.1.1892).

A meticulosa definición do seu programa de aprendizaxe e de investigación aliméntase de innúmeras e detalladas lecturas e do estudo meticuloso (Lope e o Quixote son expresamente citados nos Diarios), que o leva a anotar rigorosamente todas as preguntas para as que procurar resposta, como documenta unha anotación de 9 de febreiro de 1892 nos Diarios:

A notebook which I call Questions lies on my table and grows fatter day by day. These are the things I want to find out about Spain, books, pictures, architecture, etc.

But chiefly I must know the people and see them as they are, and as they were. The two lock and define each other. What are the inherited ideas and acts and what the outside inheritances.

As viaxes a España de Huntington forman parte do seu proxecto intelectual como aprendiz de hispanista, que acumulara un vasto coñecemento libresco previo, que conformara unhas ideas predeterminadas sobre o país e creara unhas concretas expectativas sobre o destino, baseadas tamén na lectura dos viaxeiros que o precederan. Longfellow vai ser citado no NoteBook, e dalgunha das obras de Ticknor sabemos polos Diarios que fixo unha lectura atenta ("Finished notes on Ticknor", apunta a 3 de febreiro de 1892). De Ticknor probabelmente recollerá a idea da "escravitude" relixiosa dos españois ou a importancia dos touros. Borrow será mencionado nos Diarios, ao paso polo lugar onde comezara o seu itinerario en Portugal ("Aldea Gallega, the town from which Borrow started", Diarios 1892: 83).

A partida para España realizaraa desde $\mathrm{Pa}-$ rís, por tren, segundo anota o día 4 de xullo nos Diarios. As súas reflexións mostran a consciencia a respecto dos trazos con que construíra a idea de España, unha ensoñación de tintes históricos que distará do país que finalmente irá coñecer:

At last: We are on the train leaving Paris. Every click of the rails plays an accompaniment to a dream come true. All these years! Well I must prepare to repaint my picture. Surely the thing I am about to find will be quite unlike what I have built up. I can see Spain ahead dotted with palaces and fortresses, with cathedrals and walled cities, with bearded warriors and great ladies. Of course it is all wrong. Isabella the Catholic will not be in Madrid and I am sure to miss Visigoths and Almanzor.

But there will be footprints.

É o soño da viaxe, que mostra un país imaxinado nun pasado medieval, que torna a viaxe un recuar no tempo máis do que nun desprazamento no espazo (Machado e Pageaux 1988: 40).

\subsection{As viaxes}

$\mathrm{Na}$ primeira viaxe, en 1892, Archer vai estar acompañado por William Ireland Knapp, distinguido hispanista e catedrático na Universidade de Yale $^{10}$. Os Diarios de Huntington recollen as súas vacilacións á hora de aceptar o posto de acompañante (remunerado), relacionadas en parte coa súa vida profesional, pois na altura estaba pendente da súa incorporación á Universidade de Chicago. Knapp, estudioso da obra de George Borrow, publicará no final da década, un ano despois do Note-Book, Life, Writings and Correspondence of George Borrow, derived from Official and Other Authentic Sources (1899).

Como mencionamos, o día 4 de xullo de 1892 Huntington e Knapp abandonan París en tren camiño de España, onde tiñan previsto ficar até abril do ano seguinte. A súa primeira parada será Burgos e a Galiza non chegarán até

9 Pode estar a referirse tanto a Life... ou, quizais, máis probabelmente, dado o seu interese pola literatura, a History of Spanish Literature.

10 Nos Diarios, Huntington dirá de Knapp: "Poor old K. is not a traveller!". 
agosto, provenientes de Lisboa. Nesta viaxe Archer vai provisto dun bo número de cartas de presentación e, xa en España, en setembro, chegarán aínda outras proporcionadas polo Secretario de Estado, John W. Foster, a instancias de Collis. Esta primeira visita, na que percorrerá intensamente o conxunto do país, é a fonte dos materiais que comporán o Note-Book in Northern Spain.

De acordo coa súa planificación previa, a segunda viaxe, en 1896, será, efectivamente, a dos libros. Unha nota nos Diarios así o confirma: "March 8. Madrid. Books and more books. The days when I had to search are over. They tumble in. Dealers, friends, and strangers bring them. And now come first editions and other flowers of type." Nesta ocasión Huntington chega a Madrid acompañado pola súa esposa, Helen Gates (Fernández Lorenzo 2018: 49).

A terceira viaxe da década, en 1898, iníciaa co Note-Book xa publicado. Archer arriba á Península en barco, por Xibraltar, e abandonará España con dirección a Marsella ante a inminencia da declaración de guerra dos Estados Unidos, que se produce o día 20 de abril, o día seguinte ao da súa chegada á Franza. A súa estadía centrouse no sur e, de novo, foi unha viaxe de libros -"This is a book trip", afirmará nos Diarios-, mais tamén cumprirá co seu plan de dedicala á arqueoloxía, tendo ocasión de realizar as súas propias escavacións en Itálica. Esta viaxe foi decisiva na dotación dos fondos do que será a Hispanic Society of America: coñece a biblioteca do Marqués de Jerez de los Caballeros, que compraría catro anos depois e constituirá o núcleo da colección bibliográfica da institución, e os achados da escavación en Itálica constituirán a base da súa colección arqueolóxica (Codding 2000).

No século XX, Huntington visitará España en novas ocasións e a súa presenza será obxecto de atención por parte da prensa xeral, que recollerá información dos seus desprazamentos pola Península e da súa vida social.

As viaxes acrecentarán o seu coñecemento de España, nutrirán o seu libro, proporcionarán fondos para a súa biblioteca e o imaxinado museo español, servirán para o estabelecemento dunha sólida rede de relacións con relevantes artistas, intelectuais e aristócratas, incluído o rei Alfonso XIII (Fernández Lorenzo 2018: 152153) e, sobre todo, cumprirán o seu obxectivo de coñecer a alma de España a través das súas xentes. De novo, unha anotación nos Diarios mostra o seu convencemento sobre a capacidade formativa e transformadora da viaxe:

I came to Spain, and talked to Spaniards and saw that I had lacked the clue, the clue of insight. So, at one time traveling in the coche de San Fernando, at another on the back of a mule, I wandered over the Peninsula, and let the clues unfold into certainties and at last watched large bits of history dissolve before my eyes as ice in warm water, I came to know the living Spaniard and what he could not have done. For the Spaniard of today and his ancestor of yesterday, Iberian, Roman, Goth or Arab, are like all humans, true brothers under the skin, and the spirit whispers of the departed still linger in eyes and form, in gesture and pattern of thought, in faith and superstition, in dress and dreams. And just as today you man encounter a troglodytic person on Broadway or Piccadilly so, in Galicia you may meet a Suabian or lunch in Sevilla with a reclad spirit of one of the Abencerrages. (Diarios 1898: 19)

A experiencia do viaxeiro solitario converte as percepcións conformadas desde o coñecemento histórico, dotándoas de sentido e autenticidade. A crenza na necesidade de que para estudar unha cultura é necesario o contacto directo co país e as súas xentes fará que Huntington aplique este principio co persoal que contratará na Hispanic Society e o envíe a España, Portugal e Hispanoamérica en viaxes de estudo e formación e á procura de novos materiais para o museo e a biblioteca (Proske 1965: 18).

\subsubsection{De viaxe por Galiza}

Os Diarios de Huntington son especialmente detallados na viaxe de 1892 e amplían notabelmente o relato da estadía en Galiza que traslada o Note-Book, centrado na Coruña e en Compostela: recollen o itinerario da visita desde Portugal, a súa entrada acompañado de William Knapp en tren pola fronteira de $\mathrm{Ca}$ minha e inclúen información sobre a súa estadía en lugares ausentes do libro, como Vigo. A esta cidade chegan en plena celebración dunha feira, pernoctan no hotel Continental e navegan pola ría (Diarios 1892: 86-87): "Yesterday the water was crowded with every boat to be had and steamers, little and big, from all places lined up for a regatta. K. and I got a big heavy boat and went out beside onve filled with English people. It was interesting"11.

11 Esta experiencia é probabelmente a que está recreada no poema "Exposition", publicado en Recuerdos (1949: 5253), e que está introducido por uns versos do poema “Terra a Nosa!” das Follas Novas de Rosalía de Castro. 
Esta perspectiva marítima da cidade de Vigo será completada coa ofrecida da Galiza nun documento posterior, do ano 1903, que recolle notas dunha viaxe por mar entre La Pallice e Lisboa ${ }^{12}$, con parada cando menos na Coruña. Esta descrición da paisaxe galega desde a liña de costa destaca a existencia de espléndidos portos naturais, mais carentes de comercio, unha idea reiterada tamén no Note-Book:

It is a coast of harbors this Galicia, with no commerce. Vigo, La Coruña, Carril, Ponte Vedia [sic], the navies of the world might anchor in them very well (...) It is but a short run from here to the two islands of Cies, which partly close the harbor of Vigo, another of that series of magnificent port which - like the fiords of Norway have no commerce behind them to fill them with the navies of the world. (15 e 17.6.1903)

Por outra parte, os poemarios testemuñan visitas a novos lugares: Tui e Lugo, localidades onde data diversas composicións, e talvez Ézaro, a cuxa fervenza dedica un poema.

Os Diarios do ano 1892 mostran pormenores da intendencia da viaxe, a organización dos traslados e do aloxamento -que inclúen opinións non moi favorábeis sobre as capacidades dalgúns hosteleiros ${ }^{13}$, numerosas referencias a William Knapp -a súa ansiedade por chegar á Coruña, para recoller a súa correspondenciae mencións ás persoas - principalmente estranxeiras- que encontran no camiño e ás súas opinións sobre Galiza. Por exemplo, un profesor de Ciencias aconséllaos parar en Tui, e non ir a Santiago: "We told our plans and the professor wondered that we were not to stop in Tuy wich he said was far more interesting than Santiago where there was nothing but "religion and tradition". But we explained that Tuy was for another day" (Diarios 1892: 85).

\section{Un libro de viaxes: $A$ Note-Book in Northern Spain (1898)}

A Note-Book in Northern Spain, asinado como Archer M. Huntington, é editado por G. P. Putnam's and Sons, con sede en Nova York e Londres, con data de 1898, aínda que o copyright editorial é de 1897. Como o propio autor afirma, o caderno elaborouse a partir das anotacións de viaxe de Huntington transformadas en cartas que enviou á súa nai, Arabella ("Of course this book is a bit helter-skelter, as it is practically nothing more than a number of letters to you fitted toghether, and expurgated", 16.12.97). Fóra do libro quedan as afirmacións de carácter máis confesional, subxectivo, privado e familiar e, con certeza, ao volume foron tamén incorporadas informacións (e materiais, poñamos por caso as numerosas ilustracións) que dificilmente farían parte da correspondencia privada entre ambos. Porén, as palabras de Huntington afirman a condición de testemuño real do Note-Book no marco do tópico autoral da falsa modestia.

Nunha carta a Arabella de 1898, posterior á publicación do libro e anterior á partida para a súa terceira viaxe, Archer menciona a correspondencia entre ambos: "Keep the letters; when I am a hundred they may interest me. Or burn if you think best. // But may the Lord defend me from ever writing another travel book! I leave that to the ladies" (Diarios 1898: 3-4). Fóra da consideración irónica sobre a preservación das cartas e a negativa a escribir calquera outro libro de viaxes, as afirmacións, un tanto condescendentes, sobre a feminización da literatura de viaxes manifestan a consciencia das mudanzas que estaba a experimentar o xénero, nunha altura en que comezaba a abrirse paso a súa relativa minusvalorización (Fernández Pérez-Sanjulián 2006: 370) e en que perdera a prevalencia que tivera nos Estados Unidos antes da guerra de secesión (Gifra-Adoher 2001: 35), cando era unha garantía de éxito comercial.

Certamente as escritoras viñeran contribuíndo de maneira continuada ao desenvolvemento deste xénero; ás veces partían como compañeiras dos seus homes (caso de Caroline Cushing) e a través da viaxe, accedían a un horizonte de liberdade que o medio doméstico lles negaba (Gifra-Adoher 2001: 19), ás veces como viaxeiras individuais (March 2011) que desafiaban a convención do viaxeiro solitario. A extensión do turismo e a maior presenza no espazo público das mulleres, especialmente no

12 Documentación identificada na Hispanic Society of America como "Huntington, Archer Milton. Typed letter, to $\mathrm{ADH}$, recounting travel notes on La Coruña and other ports in Spain and Portugal. Huntington, Arabella Duvall [n.p. - aboard a steamer]: 1903 Jun 13".

13 Nunha folla nos Diarios de 1892, no mes de agosto, anota os aloxamentos frecuentados na viaxe: Vigo, Hotel Continental; Santiago, Fonda Suiza (Olgiati y Mengotti); Coruña, Hotel de Europa. 
mundo anglosaxón, empurrada polo auxe do movemento sufraxista nos anos finais do século XIX e iniciais do XX, influiría no incremento do número de viaxeiras e de libros de viaxes escritos por mulleres. De feito, en datas próximas á publicación do Note-Book, son editados varios libros de viaxes de autoras norteamericanas dedicados a España: Lazy Tours in Spain (1896) de Louise Chandler Moulton, Sketches awheel in Modern Iberia (1897) de Fanny Bullock Workman -en coautoría co seu home, William Hunter Workman- e Spanish Highways and Byways (1900) de Katherine Lee Bates, a única que visitou Galiza, para o seu evidente disgusto (March 2011).

O lanzamento de A Note-Book in Northern Spain (1898) coincide cun momento de máxima tensión nas relacións entre España e Estados Unidos, a raíz da explosión do acoirazado Maine no porto da Habana en febreiro de 1898 e da posterior declaración de guerra norteamericana, que fora precedida dunha campaña de exaltación patriótica e axitación antiespañola na prensa, especialmente nos xornais propiedade de William Randolph Hearst. No Note-Book non hai mencións específicas ao clima de hostilidade entre ambos os países -aínda que si existe unha referencia á 'actual' guerra cubana (Huntington 1898: 6)-, porén a correspondencia do autor coa súa nai, algunhas anotacións nos Diarios e ocasionais declaracións á prensa esclarecen a súa posición na guerra hispano-cubana a favor de España e poñen de manifesto a preocupación de Huntington polo seu futuro, nunha liña de reflexión próxima á xeración de 98 (Fernández Lorenzo 2018: 50-60).

$\mathrm{Na}$ decisión de publicar un libro de viaxes probabelmente pesou o tipo de obra que Huntington quería escribir, de carga erudita mais que tamén achegase unha reflexión persoal sobre España, de forma que contribuíse para a súa reputación intelectual e coadxuvase a consolidar a súa condición de hispanista, e ao tempo ofrecese ao público norteamericano unha visión máis ampla e complexa do país. Desta maneira seguiría o camiño emprendido polos pioneiros do hispanismo norteamericano que, como mencionamos, visitaran España e deixaran testemuños escritos destas experiencias.

Huntington tamén sabía a clase de viaxeiro que era e que o diferenciaba da maioría. El quería coñecer realmente España, non simplemente acumular informacións e datos: quería ter un dominio completo da/s lingua/s, compartir os costumes e saber da mentalidade do pobo, vivir as experiencias da xente do común. Á idealización romántica do pobo vai unir a capacidade do viaxeiro de asumir diferentes personae, rompendo os condicionamentos de clase social, e identificando a autenticidade coa capacidade de partillar a vida dos máis humildes:

Guide books are strange impedimenta! This form of canned pabulum is about as nourishing as wasdust. My good friend S. has mastered Ford. I believe he could recite the 2 fat volumes of the 1st Edition as Scaliger the Iliad and the Odyssey. It is wonderful! (...) He has never slept in a peasant bed, or attended a small town marriage. He can read no newspaper between the lines. But he can talk for hours about Spanish railways, their gauge and freights. He knows Spanish foods, but not the relation of a daughter to a mother or a son to parents. (Diarios 1898: 67-68)

Por outra parte, Huntington procura diferenciar a súa obra dentro da cada vez maior oferta de libros de viaxe en inglés sobre España. Non só escolle un itinerario alternativo ao dominante, centrado en Castela e Andalucía e, cada vez máis, no mediterráneo, senón que adopta un modelo de obra cunha forte carga histórica, lonxe de modelos como The Land of the Castanet. Spanish Sketches (1896) -de título de seu ben expresivo-, do tamén norteamericano Hobart C. Chatfield-Taylor, responsábel dunha maior pintoresquización, se couber, da imaxe española nos Estados Unidos (Kagan 2010: 49). Este volume, de grande éxito na altura, centrábase, máis unha vez, na soleada Andalucía e na consideración do andaluz como o verdadeiro tipo de español (Chatfield-Taylor 1896: 212-213) $)^{14}$. Porén, coidamos que a elección do Norte ${ }^{15}$ non responde unicamente a

14 A obra non inclúe ningunha mención a Galiza, a pesar de citar puntualmente o galego, dentro da súa caracterización da xente común, como un tipo mellor que o reservado castelán (Chatfield-Taylor 1896: 212).

15 O eixo Norte-Sur está presente tamén nos obxectivos de estudo das súas viaxes: "My note books give me a record of a trip from Prate de Mollé, Ceret, Figueras, Rosas, Castelló de Ampurias Rosas, Figueras, Gerona Bercelona, Villanueva y Geltrú, Tarragona Tortosa and on along the sea to Cadiz. I took this trip to compare the northern with the southern type, and to note the difference between the coast civilization and that of Castile and the center" (Diarios 1893: 221). 
unha estratexia de distinción: obedece tamen á vontade de completar a visión de España que circulaba na sociedade norteamericana ${ }^{16}$-e presente tamén na súa propia obra-, construída sobre o Sur, e de afondar no coñecemento dun trazo principal da identidade española: a relixión.

A centralidade do elemento relixioso anúnciase na propia capa da obra: sobre o coiro marrón resalta en cor un pendón coa cruz de Santiago, deseño do propio autor ${ }^{17}$. Unha fotografía dunha procesión (A Spanish Religious Procession), protexida por papel cebola, abre o volume. Logo da dedicatoria á nai e o breve prefacio que explica a intención xeral da obra e as súas características, os dezaseis capítulos do Note-Book trazan un percurso que se inicia na Coruña e conclúe en Roncesvalles, pasando por Astorga, Oviedo, Plasencia, Yuste, Madrid, Teruel, Zaragoza, Huesca, Jaca, Panticosa (cun capítulo específico dedicado ao mosteiro de San Juan de La Peña), Leyre, Pamplona e Estella. A organización en capítulos segue o itinerario e os seus títulos cínxense aos nomes das localidades visitadas ou do traxecto realizado, con catro excepcións: o capítulo I ("In general"), de carácter introdutorio; o capítulo II, titulado "Galicia"; o VII, "The Bull-Ring"; o IX, "The lovers of Teruel" e o XIII, "San Juan de la Peña-The cave of the Virgin". Neste itinerario construído destaca a presenza de lugares relevantes pola súa significación histórica mais principalmente relixiosa (fitos sinalados dos itinerarios xacobeos, sitios de relevancia devota) e a singular inclusión de Madrid neste mapa do norte, que trae consigo a presenza dun longo capítulo dedicado aos touros, o deporte nacional, resultado da modernización de tradicións herdadas de romanos e mouros, segundo Huntington (1898: 96) ${ }^{18}$, ilustrado con profusión de retratos de figuras do toreo.

No prefacio, Huntington xustifica a elección do Norte, considerado xeralmente como carente do atractivo romántico do Sur. Destaca
Santiago -"the early Christian Cordova"-, Oviedo, Zaragoza e as pequenas cidades dos Pireneos ("there is a wealth of tradition and local interest unsurpassed even in the South"). $\mathrm{O}$ eixo Norte-Sur eríxese en referencia para explicar España, e isto fai que os valores do descoñecido Norte sexan esclarecidos a partir do Sur. Se España é entendida como medieval (unha idea construída principalmente sobre elementos casteláns) e oriental (a partir da visión de parte de Andalucía), o Norte vai ser explicado a partir da chave relixiosa e medieval.

Igualmente no prefacio Huntington explica o esmero e o coidado posto nas ilustracións -compostas por materiais alleos e orixinais, con fotografías especialmente tiradas para a ocasión-, agradece a axuda aos españois, amigos e estraños, que encontrou nas súas viaxes e explica a condición do libro de síntese das notas tomadas sobre a marcha no curso de varias viaxes. Cómpre insistir en que o NoteBook non pretende ser a crónica dunha única viaxe real, mais trazar un itinerario a partir das experiencias reais de visita dos lugares citados: por tanto, prodúcese a ficcionalización da experiencia da viaxe. Un exemplo: no NoteBook, Huntington chega á Península en barco, ao porto da Coruña, logo dunha travesía de 15 días desde A Habana; porén, como comentamos, nas viaxes de 1892 e 1896 chegara a Madrid en tren procedente de París.

O Note-Book in Northern Spain é unha conxunción de saber erudito (con base en fontes bibliográficas, explícitas ou non), experiencias de viaxe e impresións persoais. $\mathrm{O}$ aspecto gráfico é tamén relevante na obra que, alén de fotografías $^{19}$, inclúe gravuras. Se en toda narrativa de viaxe hai unha parte de adquisición cultural e outra de confesión individual (Machado e Pageaux 1988: 47), os dous termos van estar notabelmente equilibrados en Huntington que, pola contra, fuxirá da acumulación de datos presente noutros libros do xénero.

16 Obxectivo que parcialmente debeu conseguir: a publicación foi recensionada na prensa, como se deduce dunha carta a Arabella ("Thank you for the clippings from the Sun, Times, and Tribune on my Note-Book; also the ones from The Sketch", Diarios 1898: 108).

17 "Got my first copy of the Note Book in Northern Spain, the cover design of which I made myself" (Carta a Arabella, 16.12.1897).

18 O autor é consciente da crueldade do espectáculo, mais considera a celebración dunha corrida como o mellor lugar onde observar o carácter español.

19 O interese pola fotografía como forma de rexistro documental terá a súa réplica na Hispanic Society, que promoverá misións fotográficas como a de Ruth Matilda Anderson en Galiza. Huntington verá na fotografía un medio de conservar o testemuño dunha realidade que estaba a mudar e de formas de vida en extinción. 


\section{España e Galiza no Note-Book}

\subsection{Unha idea de España}

Nas páxinas do Caderno, unha idea central é a da complexidade, histórica e coetánea, de España; unha 'nación composta' que, para Huntington, ten no catolicismo o elo de unión entre as diferentes identidades:

Here the fragmentary middle-age condition of Italy was repeated. Cataluña, Aragon, Castile, Andalucia, are not mere geographical terms. Each presents its distinct national and special character. Tradition, habits, sports, costume, have all their peculiar expression and local difference.

The brawny Aragonese, the harsh-tongued industrious Catalan, the Celtic-souled Gallegan, the dignified gentleman of Castile and Leon, the fiery, knife-loving Andaluz, are united under one name and one religion as Spaniards and Catholics into a loosely knit whole, wherein the seeds of revolution and ism take ready root. (Huntington 1898: 3)

A alusión á diversidade de España e dos españois, identificados como pobos diferentes con caracteres nacionais específicos, é unha constante nos discursos dos libros de viaxes, desde Richard Ford-que no Hand-Book (1845) constata que non existe un único concepto de españolidade e que as diferenzas entre xentes e territorios son culturais, lingüísticas, de indumentaria, hábitos e clima-, até L(ily) Higgin que, en Spanish Life in Town and Country (1902), afirma que a variedade entre zonas podería facer pensar en tratárense de reinos diferentes (Egea s.d.). Nos Diarios, Huntington insiste nos diversos pobos que habitaran historicamente a Península e na pegada que foran deixando nela, de maneira que, en ocasións, os españois son vistos como unha especie de compendio de historia viva, un pobo que, por estas circunstancias, ten un carácter nacional híbrido ("And the Spaniard is full of
Arabic blood. But the Spaniard is full of many bloods", Diarios 17.1.1892), unha apreciación común nos viaxeiros que visitan España desde finais do século XVIII (Egea s.d.).

No caso de Huntington, a consciencia das diferenzas dentro de España responde ao seu coñecemento histórico mais tamén ao seu seguimento dunha actualidade política e cultural en que os debates rexionalistas tiñan unha forte presenza, e que o autor contempla con certa preocupación pola ameaza de ruptura da unidade do Estado que podían supor (Fernández Lorenzo 2018: 61). Porén, é a visión dunha España histórica e culturamente plural a que vai estar presente na Hispanic Society, e terá un reflexo gráfico no encargo que fará ao pintor Joaquín Sorolla para a creación da serie das Provincias de España (hoxe rebautizada como Visión de España) en cadros de grande formato, que o pintor completa en 1919 e son expostos por vez primeira en 1926.

Aínda que Huntington contempla o catolicismo como un elemento principal da identidade española non é para el a causa da decadencia do país, como acontecía, en boa medida, na opinión pública norteamericana ${ }^{20}$. No seu parecer, as razóns do declinio español encóntranse, fundamentalmente, na carencia de espírito comercial que ameazaba con deixar a unha España que perdera os seus territorios de ultramar, isolada e fragmentada (Diarios 1898: 27).

\subsection{Unha idea de Galiza}

Como xa indicamos, dos dezaseis capítulos da obra, dous son dedicados especificamente a Galiza: o segundo, titulado "Galicia" e o terceiro, "Coruña-Santiago", un dos máis extensos da obra. En total, unhas 35 páxinas, ilustradas por 15 imaxes $^{21}$, que combinan a experiencia da viaxe (os medios de transporte que utilizou, referencias ao aloxamento, a apreciación dalgún alimento) e algunhas anécdotas,

20 Nos Diarios (1893: 229) recolle un seu encontro en Andalucía cun grupo de americanos que expresan esta opinión: "It's all this Catholicism that has ruined Spain" said an old gray beard. I asked him whether Mormenism had yet overcome the American people. "Mormenism" he said "is at least based on the bible, while Catholicism is based on a Pope" I said I had not thought of that!".

21 As ilustracións son Lugo (11), Arrow head from the lacuna antela (12), Remains of a dolmen at nova (12), Tower of Hercules (16), Reconstructions of the tower of Hercules (16), Gallegan peasant (17), A Gallegan ox-team (22), The cathedral of Santiago (25), Santiago (31), Theodemir discovering the tombs (34), Suggested restoration of original structure (37), Plans of tomb (39), Mosaic from the subterranean church (41), Where the relics were found (43), Coruna (45). En total, oito vinculadas a Santiago (principalmente á catedral), dúas á Torre de Hércules, tres ás cidades - excluíndo Compostela-, dúas á prehistoria e dúas ao mundo rural. A maioría son gravuras tiradas de Galicia de Murguía e de Recuerdos de un viaje a Santiago de Galicia de Fita e Fernández-Guerra (1880), e algunhas outras fotografías propias. 
con abundante información histórica e cultural. Cada capítulo ábrese cunha citación -de $A$ Lady's Journey into Spain (1692) e da Galicia de Manuel Murguía (1888) ${ }^{22}$-; conxuntamente ambas serven para introducir algunhas ideaschave: a condición singular de Galiza, a súa pobreza e a monumentalidade de Compostela.

"This little-out-of-the-world Galicia". Esta frase podería sintetizar a visión xeral de Huntington: un lugar isolado, fóra do tempo, que precisamente por esa (suposta) inmutabilidade desde a Idade Media, presenta interese: "But Galicia has, nevertheless, a somewhat considerable interest for us if it be only in the study of those influences or lack of influences which bring her to us so unchanged from the middle-age turmoil" (Huntington 1898: 11).

Isolamento, inmutabilidade, falta de contacto con outros pobos -singularmente cos árabes-, e ausencia de participación en eventos históricos relevantes son algunhas das condicións que definen unha Galiza ensimesmada e pura. A esta condición de illamento vén sumarse a súa singularidade no conxunto de España: catro provincias e un país que "is as little Spanish in tongue, manners or habits as is well possible" (Huntington 1898: 10). Un lugar pouco romántico que servirá como preparación da visita ao Sur e que, en certa forma, se configura como a súa antítese completa.

A idea de pobreza estará vinculada ás condicións de vida das persoas, mais tamén á falta de aproveitamento comercial do país. Huntington describe os galegos como unha raza robusta de persoas, moi pobres ${ }^{23}$, nun estado primitivo de desenvolvemento, apaixonados pola súa terra e extremadamente orgullosos do seu (lingua, terra, literatura son expresamente mencionados), melancólicos e morriñentos, e que ten a devoción como principal entretemento. Unha terra de choiva e néboa cunha paisaxe extremadamente fermosa, e perto de 3000 ríos e regatos ${ }^{24}$. A referencia ao atraso material é complementada con información sobre a produción agro-forestal (patacas, millo, cebolas, piñeiros, exportados a Inglaterra) e sobre a carencia de movemento comercial nuns portos que son a terceira parte dos de España. Ante a vontade de dous vascos de que se constrúa un ferrocarril entre A Coruña e Santiago, Huntington móstrase escéptico pola súa utilidade, pois só podería transportar algúns produtos da granxa e moi poucos pasaxeiros. Mais o autor destaca tamén a existencia dun mal goberno.

En certo sentido, a idea de pobreza e o destaque da relixión son o resultado de avaliar Galiza (e talvez calquera país visitado) en función da idea de progreso e dun ideal de cultura cada vez máis laico, o que vén facer realidade a concepción da viaxe como recuar no tempo (Machado e Pageaux 1988: 40). Un recuar no tempo que neste caso se materializará na condición medieval -arquitectonicamente plasmada-de Compostela, lugar de repouso dos restos do Apóstolo Santiago, razón -única, podería deducirse do discurso de Huntingtonpara ser Galiza coñecida mundialmente.

\subsubsection{O celtismo: Galiza e Irlanda}

Para Huntington (1898: 10), Galiza é inequivocamente celta ("It is Celtic to the last degree"), unha condición reiterada para explicar as súas orixes, certas lendas e algúns aspectos antropolóxicos. Porén, as referencias ao celtismo galego non son só librescas, nin referidas unicamente ao pasado, senón que se converten en chave para explicar un certo carácter nacional, e os comportamentos e as actitudes dalgunha das persoas que encontra no país.

A comunidade celta xustifica a existencia de vínculos especiais entre Galiza e Irlanda -unha analoxía presente no pensamento rexionalista e longamente desenvolvida por Murguía-, e explica a existencia de trazos comúns nos caracteres nacionais. $\mathrm{O}$ encontro co maioral Juan Díaz dá pé para alcumar Galiza de nova Irlanda e o galego de segundo irlandés: "not the Latin dignity of Castile but rather the gravity which among these sturdy people of the misty north country, where nature has fashioned a new Ireland and a second Irishman, masks a Celtic explosiveness." (Huntington 1898: 18). A analoxía Galiza-Irlanda vai da man da relación de oposición Galiza-Castela, un antagonismo que

22 "For you must know that Galicia is so poor and mean a Countrey, that there's no place for bragging" e "Todo en esta ciudad es reposado y fuerte como el granito de sus monumentos" (Murguía 1888: 350).

23 Na súa visita de 1903 describe a multitude de esmolantes que agardaban no porto a chegada do barco.

24 Esta descrición repetirase nas notas da visita de 1903: "Along their baes in the sunlight the white line of angry foam churns on forever, and upon their tops hang all the mists of the Atlantic that make of Galicia the dreary, rainy, dull land that it is". 
estaba cada vez máis presente no discurso rexionalista, aínda que Huntington non lle dea un sentido estritamente político.

Certamente, as referencias a Irlanda nos viaxeiros a Galiza eran frecuentes. O propio Richard Ford mencionara como a pobreza dos campesiños galegos, en contraste coa riqueza da terra, lle lembraba a illa (Egea s.d.). Huntington tamén levará a comparación á actualidade política, para estabelecer irónicas comparacións entre a contestación política dos irlandeses e a do maioral, que arenga (en galego, nota o autor) unha vintena de persoas congregadas nunha taberna: a elocuencia de Díaz contra os tributos que esmagan os pobres é similar á exhibida por [Daniel] O'Connell ou Feargus O'Connor nos seus grandes mitins e co mesmo resultado, dirá, ningún.

Por tanto, o celtismo é utilizado como un elemento definidor da identidade galega, do carácter galego mais, a través da comparación con Irlanda, é tamén dotado de contido político.

\subsubsection{Historia, arqueoloxía e folclore}

Historia, arqueoloxía e folclore son as disciplinas que centran o discurso académico do NoteBook. A historia está presente principalmente para explicar as orixes das cidades da Coruña e de Compostela e os elementos patrimoniais que as identifican e representan: a coruñesa Torre de Hércules e a catedral de Santiago de Compostela. Na arqueoloxía, son mencionados os restos prehistóricos das covas do rei Cintoulo [sic] ou de cidades sulagadas en Doñinos e Antela. No caso do folclore, destaca os seus vínculos co mundo celta, e quere ilustrar a súa importancia e antigüidade reproducindo a lenda dunha moura do monte d'as croas [sic] en San Martín de Salcedo (Pontevedra), traducindo a narración realizada por Murguía en Galicia (1888).
Un amante da arqueoloxía como Huntington non podía deixar de lamentar a falta de estudo científico dos achados realizados e o desleixo con que foron tratados, como lamenta, en xeral, a falta de traballo científico, tamén no caso do folclore.

\subsubsection{As cidades}

$\mathrm{Na}$ aproximación a Compostela, Huntington combina a narración de vivencias da viaxe con información histórica e erudita, baseada nunha fonte principal: Recuerdos de un viaje á Santiago de Galicia (1880) de Fidel Fita y Colomer e Aureliano Guerra y Orbe ${ }^{25}$. Deste volume toma a reprodución da miniatura de Teodomiro facendo a descuberta do sepulcro, presente no Tumbo A e na Historia Compostelana, e traduce a prolixa descrición dos autores ${ }^{26}$. Como o enfoque do Note-Book é esencialmente xacobeo, a propósito de historiar a descuberta das reliquias e o proceso de erección da catedral, alén da Historia Compostelana, son mencionados a Crónica General de España de Ambrosio Morales e os traballos do Padre Mariana ${ }^{27}$.

Huntington inclúe tamén a narración de episodios lendarios, como a intervención do apóstolo na dubidosa batalla de Clavijo e o saqueo de Almanzor ${ }^{28}$-episodio sobre o que ironiza pola ausencia da intervención de Santiago para se protexer a si propio. A que podería ser unha longa historia xacobea é conscientemente eludida para centrarse só nos episodios máis novelescos, en concreto, as medidas tomadas para protexer as reliquias do santo do eventual asalto de Francis Drake e a súa redescuberta no século XIX, coa realización da análise química que non descartou que puidesen ser, efectivamente, de Santiago e os seus discípulos. Desta maneira, Huntington incorpora a noticia das accións levadas a cabo polo cardeal Payá -sen mencionalo- que permitirán reactivar as peregrinacións xacobeas ${ }^{29}$.

25 A obra é, entre outras cousas, unha narración da viaxe a Compostela desde Portugal, o mesmo itinerario que fixera Huntington en 1892.

26 A dependencia da obra de Fita e Guerra ponse de manifesto tamén na incorporación ao Note-Book de varias ilustracións, adaptadas no seu tamaño: "El sepulcro de Santiago" (Fita / Fernández-Guerra 1880: 70), un "Fragmento de mosáico, en el pavimento de la iglesia subterránea" (Ibid.: 71); a citada miniatura de Teodomiro (Ibid.: 72); "Restauración congetural del sepulcro apostólico primitivo" (Ibid.: 76) e o "Reconditorio ó escondido lugar donde se han hallado las reliquias, en la catedral de Santiago" (Ibid.: 82).

27 Cita tamén Dante e Burke para testemuñar a relevancia cultural e relixiosa de Santiago.

28 March (2011: 131) lembra que Almanzor é unha referencia habitual nos libros de viaxes anglosaxóns que tratan de Compostela.

29 Huntington escribirá algúns poemas de asunto xacobeo, como "The stone" e "La columna. Reverence of hands in Santiago", recollidos en Collected Verse (1953). 
Na aproximación á Coruña, destaca a antigüidade da cidade vinculada co relato das orixes da torre de Hércules e a súa importancia como referencia para a navegación e o comercio desde a época fenicia. Isto permítelle facer un excurso sobre a riqueza en metais (ouro, prata, estaño) de Galiza na antigüidade. O seu discurso vai ilustrado con imaxes do monumento: as reconstrucións hipotéticas obra de Murguía, e unha fotografía contemporánea.

Este discurso sobre a Coruña verase completado coa mención da visita á tumba de Sir John Moore -"the only sight of interest to the two Englishmen who were with us"- na viaxe por mar do ano 1903.

Como sinalaremos na sección 5.2.5, ambas cidades son tamén escenarios de anécdotas narrativas protagonizadas polo autor: o encontro co sereno nun paseo nocturno por Compostela e a arenga política do maioral nunha taberna coruñesa.

A impresión que causaron en Huntington as únicas dúas cidades galegas citadas no $\mathrm{No}$ te-Book non foi moi favorábel. Santiago tiña "The calmness of a dying city" - como todas as cidades do Norte-, unha afirmación que se converterá en tópica ao referirse á cidade do Apóstolo -repetida, por exemplo, por Georgiana Goddard King, que a considera unha cidade morta (March 2011: 138). Que a cidade compostelá non era o grande centro de peregrinación que fora na Idade Media, era algo que Huntington non descoñecía -Borrow (1842) xa se referira ao escaso número de peregrinos-, mais iso non evitou a decepción ante a moi pequena e calma cidade que Santiago era no século XIX, a pesar de que puidese visitar a universidade e comprar algúns libros. A Coruña non contribuíu moito a mellorar a súa impresión: "[a] sombre corner of Spain", cun clima neboento e chuviñento. Anos despois, na citada viaxe de 1903, as súas anotacións espellarán as mesmas impresións sobre a cidade herculina. Perante o comentario dun pasaxeiro sobre as mudanzas que encontraría na cidade, Huntington escribe:

What the change consisted in I have not yet been able to decide. If it was that the streets were a little more dirty, that the people seemed a little less cheerful, that the general air of desolation was greater, perhaps he was right. In nothing else is it different from the Coruña I have known in the past.

\subsubsection{Lingua e literatura}

Como vimos, Huntington define desde o inicio Galiza como un país singular dentro de España: un certo carácter nacional, a paisaxe -apenas caracterizada, só mencionada-e unha lingua propia -denominada ocasionalmente como dialecto. Os excursos históricos, presentes para tratar outros aspectos da viaxe, limítanse no caso da lingua a mencionar a súa condición de nai do portugués ("the child having become slightly refined and broadened by contact with the world").

Huntington semella dominar o galego, se nos atemos ao relato da arenga do maioral, cando o uso do galego para dirixirse aos seus paisanos non impide que o entenda. Como moitos dos viaxeiros anglosaxóns, comezando por Ford, costuma mechar o inglés con termos en español ou en galego (March 2011: 136), un trazo non só estilístico senón que pretende subliñar unha competencia lingüística que habilita o narrador/viaxeiro para un coñecemento realmente de primeira man do lugar que visita. Con todo, a lingua galega fai escasa aparición nestas páxinas: mo[r]riña, [monte] d'as croas, pan de mais son os únicos termos incluídos no relato da viaxe en Galiza.

Aínda que menciona a existencia dunha literatura, e do orgullo dos galegos por tela, non hai referencias de ningún tipo a obras ou autores, e non porque Huntington os descoñecese ${ }^{30}$. De facto, a única escritora mencionada nas páxinas galegas do Note-Book é Emilia Pardo Bazán, cunha alusión á súa novela Morriña, a propósito da caracterización do pobo galego.

\subsubsection{A experiencia da viaxe}

Se a narrativa de viaxes decimonónica pode ser vista como unha combinación de feitos históricos, observacións contemporáneas e novela (Gifra-Adoher 2001), cada unha destas modalidades discursivas vai ter a súa correspondencia na modalización narrativa. Se o discurso académico é vehiculado a través dunha impersoal terceira persoa, as observacións do viaxeiro van adoptar a fórmula do eu protagonista que recrea a experiencia da súa viaxe.

30 Algúns poemas recollidos en Collected Verse (1953) mostran familiaridade coa lingua e coñecementos de literatura galega contemporánea: cita estrofas de Rosalía de Castro e de Barcia Caballero e versos populares compilados por Rodríguez Marín. 
Esta visión do viaxeiro dos dous capítulos galegos do Note-Book vai construírse arredor dunha serie de topos: as condicións do transporte, o aloxamento, a comida, os panoramas contemplados nos desprazamentos, as construcións arquitectónicas etc.

O Note-Book alude á longa e dura travesía en barco desde A Habana, ao traslado en carrilana entre A Coruña e Santiago, ao retorno en carruaxe, a presenza das parellas da Garda Civil ao longo do camiño, á visión de dous peregrinos descalzos etc. Sobre o aloxamento comparecen os tópicos habituais sobre a súa mala calidade -de inicio Huntington lembra a mala fama dos hoteis en Galiza-, pois o propietario do hotel na Coruña aínda non aprendera a modernizar o negocio e adaptalo ás esixencias do pintoresco, como si acontecía nun Sur de novo utilizado como termo de comparación. Da comida, sinala como o pan tiña fama de ser de boa calidade mais áchao acedo e o pan de maís considérao gomoso e mao de dixerir. Da observación nos traxectos entre as cidades, destaca os traballos das mulleres no campo, un feito que non merece especial comentario, as construcións en pedra e a ausencia da utilización da madeira, que interpreta como resultado dunha carencia.

Mais a imaxe de Galiza no Note-Book está tamén recreada a través de pequenos cadros narrativos, onde o eu protagonista cede ante o eu testemuña, que traslada escenas corais, coa presentación de diversas personaxes, algunhas viaxeiras polo país, como el propio, ou descritivos. $\mathrm{O}$ episodio na taberna co maioral, xa referido, as conversas cos pasaxeiros da carrilana, o paseo nocturno por Compostela e o encontro co sereno son exemplo dos primeiros. A descrición do mercado popular que atravesa na Coruña, a preparación da carrilana polo zagal, a parada no camiño para beber auga nunha casa labrega -que serve para describir a convivencia entre animais e persoas nun moi reducido espazo-, e o encontro cun carro de bois atascado son exemplos do segundo. Son escenas dunha Galiza eminentemente rural e en certa forma atemporal, que cumpren coa necesidade de completar a erudición coa presenza de anécdotas que personalicen a experiencia da via$\mathrm{xe}$, que mostran un viaxeiro que toma contacto cunha realidade ben diferente da que constituía o seu contorno de relacións sociais no seu país. Neste sentido é inevitábel que apareza unha visión de clase no relato, que nunca mostra un intercambio cos seus pares, que tamén os había, e cos que tivo relación, senón en Galiza, si no conxunto de España.

\section{Cabo}

As páxinas do Note-Book in Northern Spain deixan constancia da condición diferente e singular de Galiza dentro de España, unha diferenza asentada en características como a lingua, un carácter nacional, e costumes propios. Esta singularidade transfórmase en afinidade con Irlanda e os pobos celtas, pois para Huntington é o celtismo a principal característica da identidade cultural galega.

A falta de espírito comercial na que encontrara a explicación do declinio de España vai mostrarse en Galiza na pobreza das xentes, na visión duns portos sen tráfico de mercancías e nos moi escasos produtos que poderían ser obxecto de comercio.

A visión de fondo dunha Galiza rural é completada coa visita a dúas cidades, A Coruña e Santiago de Compostela, e a atención prestada aos seus monumentos máis representativos, a Torre de Hércules, como símbolo talvez desa apertura ao comercio marítimo en tempos pasados, e a catedral que custodia os restos do Apóstolo, orixe do mito xacobeo que centra boa parte da erudición do Note-Book, como símbolo do espírito relixioso que Huntington ve característico dos galegos.

A condición medieval da cidade, estendida ao conxunto do país, traduce a idea da Galiza atemporal que Huntington recrea e que moitos visitantes posteriores glosarán.

O coñecemento erudito debedor das obras de Murguía e de Fita e Guerra vai completarse cunha visión persoal de Galiza produto do seu contacto directo coas xentes, o campo e as cidades, como el mesmo quixera.

En certa forma, as páxinas galegas do NoteBook poden ser lidas como un precedente de dúas empresas que Huntington impulsará desde a Hispanic Society of America: a publicación de Georgiana Goddard King The way to Saint James (1920), obra de referencia de novas peregrinaxes xacobeas, e as viaxes de Ruth Matilda Anderson na década de 20, que terán como resultado un amplo e valioso fondo fotográfico e a publicación de Gallegan Provinces of Spain: La Coruña and Pontevedra (1939), testemuños desa Galiza atemporal que xa non existe. 


\section{Referencias bibliográficas}

Bennet, Shelley (2013): The Art of Wealth: The Huntingtons in the Gilded Age. San Marino: Huntington Library Press.

Chatfield-Taylor, Hobart C. (1906 [1896]): The Land of the Castanet. Spanish Sketches. New York: Duffield \& Company.

Codding, Mitchell A. (2000): “Archer Milton Huntington: Champion of Spain in the United States”, en R. Kagan (ed.), Spain in America: The Origins of Hispanism in the United States. Urbana and Chicago: University of Illinois Press, pp. 142-170.

Egea Fernández Montesinos, Alberto (dir.) (s.d.): La imagen de España de los viajeros extranjeros. La colección de libros de viaje del Instituto Cervantes de Londres, https://cvc.cervantes.es/literatura/viajeros/default.htm [consulta: 31/05/2019].

Fernández Lorenzo, Patricia (2018): Archer M. Huntington. El fundador de la Hispanic Society of America en España. Madrid: Marcial Pons Historia / Fundación Alfonso Martín Escudero.

Fernández Pérez-Sanjulián, Carme (2006): "A literatura de viaxes nos contextos de emerxencia literaria: o caso galego", en F. Salinas Portugal e M ${ }^{a}$ A. Tavares Maleval (eds.), Estudos galego-brasileiros 2. A Coruña: Servizo de Publicacións da Universidade da Coruña, pp. 365-387.

Fita, Fidel e Aureliano Fernández-Guerra (1880): Recuerdos de un viaje a Santiago de Galicia. Madrid: Imprenta de los señores Lezcano y Cía.

García-Mazas, José (1962): El poeta y la escultora: la España que Huntington conoció. Madrid: Revista de Occidente.

Gifra-Adoher, Pere (2001): Between History and Romance: Travel Writing on Spain in the Early Nineteenth-Century United States. Madison: Fairleigh Dickinson University Press.

Huntington, Archer M. (1898): A Note-Book in Northern Spain. New York \& London: G. P. Putnam and Sons.

Jacobs, Michael (s.d.): "Viajeros en la España moderna: de la Ilustración a la actualidad", en A. Egea Fernández-Montesinos (dir.), La imagen de España en los viajeros extranjeros: la colección de libros de viajes del Instituto Cervantes, https://cvc.cervantes.es/literatura/viajeros/articulos/michael_jacobs. htm [consulta: 31/05/2019].

Jaksić, Iván (2007): Vén conmigo a la España lejana. Los intelectuales norteamericanos ante el mundo hispánico 1820-80. Santiago de Chile: Fondo de Cultura Económica.

Kagan, Richard (1998): "El paradigma Prescott: la historiografía norteamericana y la decadencia de España", Manuscripts. Revista de historia moderna 16, pp. 229-253, https://ddd.uab.cat/record/39578.

(2010): "The Spanish Craze in the United States: Cultural Entitlement and the Appropriation of Spain's Cultural Patrimony, ca. 1890-ca. 1930", Revista Complutense de Historia de América 36, pp. 37-58, DOI: https://doi.org/10.5209/rev_RCHA.2010.v36.2.

(2019): The Spanish Craze. America's Fascination with the Hispanica World, 1779-1939. Lincoln: University of Nebraska Press.

Machado, Álvaro Manuel e Daniel-Henri Pageaux (1988): Da literatura comparada à teoria da literatura. Lisboa: Edições 70.

March, Kathleen N. (2011): "A Galiza dos séculos XIX e XX: a ollada anglosaxona”, en C. Fernández Pérez-Sanjulián (ed.), Viaxes e construción do pensamento: viaxes e viaxeiros na Galiza anterior a 1936. A Coruña: Servizo de Publicacións da Universidade da Coruña, pp. 127-145.

Murguía, Manuel (1888): Galicia. Barcelona: Establecimiento tipográfico-editorial de Daniel Cortezo y Cía.

Proske, Beatrice Gilman (1965): Archer Milton Huntington. New York: Hispanic Society of America. 